\title{
The heterogeneity of social outcome following head
} injury

\author{
D A V I D DO D W E L L
}

From the University Department of Neurology, Manchester Royal Infirmary, Manchester, UK

SUMMARY This study compares nine different measures of social outcome applied to 56 patients seen 0 to 4 years after head injury. Social outcome was found to be heterogeneous: correlations between the measures and a principal components analysis both indicated that time off work (as a percentage of time since injury) was independent of most other measures of social performance. In the group studied, the best measures of non-work social performance were the Katz Adjustment Scales form 2 (socially expected activity) and Bond's Social Scale, which both showed good agreement between subject and informant ratings. If a single outcome measure is desired (to include work and non-work social performance), the most suitable measure was found to be the Glasgow Outcome Scale, original and extended versions.

In the last two decades, head injuries have become established as an important source of morbidity and mortality, especially in children and young adults, ${ }^{1-4}$ and a problem worthy of study. ${ }^{5}$ The increasing amount of work being carried out in this field has emphasised a need for satisfactory measures of outcome.

Social outcome is important not only in itself, but as a summary and as a utilitarian measure. Social handicaps have been conceptualised as the ultimate expression of diseases, impairments and disabilities, ${ }^{6}$ and as a final common pathway for the expression of psychiatric disorder. ${ }^{7}$ They also offer a practical guide to the need for services.

The simplest and most commonly used measure of social outcome after head injury is time off work. ${ }^{8-13}$ The disadvantages of this method are firstly that it is only applicable to subjects already in work (thus excluding schoolchildren, the unemployed, housewives and old age pensioners) and secondly, it is affected by other pressures, such as the presence of active rehabilitation schemes, financial commitments, availability of welfare benefits, and the possibility of compensation. Other indices have been reported, including the use of Social Scales, ${ }^{14-17}$ Occupational Therapy assessment ${ }^{18}$ and subjective reports of work

Address for reprint requests: Dr D Dodwell, Department of Psychiatry, Manchester Royal Infirmary, Oxford Road, Manchester M13 9WL, UK.

Received 6 July 1987 and in revised form 10 February 1988. Accepted 26 February 1988 capability and domestic friction. ${ }^{19} \mathrm{~A}$ simple and welldefined measure, the Glasgow Outcome Scale, has been described by Jennett and colleagues ${ }^{2021}$ for overall assessment of outcome after head injury, including social function. More recently, a new outcome schedule has been devised by Livingston and Livingston, ${ }^{22}$ which includes subscales on work function and activities of daily living.

In considering the field of social assessment, it seems reasonable to examine measures already in use by psychiatrists for studying other neuropsychiatric disorders. Reviews of the available measures ${ }^{23-25}$ suggest well over 20 acceptable scales. This abundance of measuring instruments also illustrates the fact that there is some variety in the interpretation of the term "social". Different scales cover different social domains, such as marital relationships, leisure pursuits, finances and housing. As with time off work, not all domains are applicable to all subjects.

Apart from deciding which domains of social function to cover, there is also some variation in the recommended origins of the data. In psychiatry, recognised data sources include either an informant or the subject himself, using either an interview schedule or a self-report questionnaire. Jennett ${ }^{26}$ has emphasised the importance of combining both accounts in the assessment and outcome after head injury. In old age psychiatry, attention has also been paid to testing the actual performance of activities of daily living. ${ }^{27} 28$

Finally, in rating social function it is clear that there is some ambiguity about whether certain phe- 
nomena are social (interpersonal) or psychiatric (intrapersonal). For example, irritability and social withdrawal are common psychiatric symptoms, which could equally well be construed as aspects of social function. In addition to these ambiguous features, some scales further complicate the issue by including more obviously psychiatric items, such as guilt, distress and dissatisfaction.

Unfortunately, both in psychiatry in general and in the field of head injury in particular, there are few studies comparing different social outcome measures and thus an informed choice cannot be made. The variety of assessments available also makes it hard to compare studies which have used different measures.

A study of head injured patients was carried out to measure social outcome and its determinants. In view of the importance of the outcome parameter, and the complexities of the subject, it was decided to apply several different measures to the same subjects. This report concerns a comparison of the results obtained from the different scales used to measure social outcome.

\section{Methods}

\section{Patients}

The subjects consisted of patients seen after sustaining a blunt head injury in adulthood (age 16 years or over). They were a consecutive series of patients who were referred for neuropsychological evaluation within 4 years of injury and who were able and willing to cooperate with psychiatric assessment (including an interview with an informant). Complete measures were not obtained on all subjects owing to changes in the protocol during the study.

All the patients had been referred to the Neurology Department and had been seen by a neurologist. The main sources of referral were from general practice, from other departments in the hospital, and from solicitors requesting medico-legal reports. A few patients were also referred by consultant neurologists from other hospitals. In general, the reason for referral was the assessment of post-traumatic sequelae, particularly where there was a question of epilepsy or where complaints by the patient or relatives appeared excessive to the referring doctor. Reasons for referral for neuropsychological assessment were usually for the evaluation of memory and learning disorders or of personality change. Patients did not come from a defined catchment area: the vast majority were from the North West Region and most were from the Greater Manchester Area.

\section{Procedure}

The assessment of each patient included a detailed history of the injury and its sequelae, standardised cognitive tests, a standardised psychiatric interview (the Present State Examination $^{29}$ ), assessment of premorbid personality and a physical examination, as well as the assessments of social functioning. The informants' data also included a history and assessment of premorbid personality; information for rating the social scales was obtained at the same interview. Seven scales of social functioning were used: they are described in the following paragraphs.
Four scales are based on checklists, which were included in the interview procedure. The items covered in the scales are summarised in table 1 , which shows that there is some overlap between the scales, but no scale is entirely redundant.

The Modified Crichton Royal Behavioural Rating Scale (MCRBRS) was developed by Wilkin and Jolley ${ }^{30}$ from the Crichton Geriatric Behaviour Rating Scale ${ }^{31}$ and consists of 10 items rated on 4 or 5 point scales. Detailed guidelines for ratings are provided by Charlesworth and Wilkin. ${ }^{32}$ It has been used in rating psychogeriatric patients and concentrates on the most basic abilities such as continence and communication. The information is obtained from a care-giver such as a ward nurse or officer-in-charge of an old persons' home. The time period is not specified.

The Current Behaviour Schedule (CBS) was used by Owens and Johnstone, ${ }^{33}$ and a slightly modified form has since been published. ${ }^{34}$ There are 23 items, most of which are rated on 3 point scales. It was designed for use with adult chronic schizophrenics and includes psychotic symptoms such as hallucinations as well as observable behaviour. It is also based on information obtained from a care-giver, such as a ward nurse or relative. The time covered is the last 6 months.

The Katz Adjustment Scales (KAS) ${ }^{35}$ include two forms ( $R 2$ and S2), respectively designed for informant and subject ratings of the performance of socially expected activities. Each form consists of the same 16 items rated on 3 point

Table 1 Summarised content of checklist rating scales

\begin{tabular}{|c|c|c|c|c|}
\hline \multirow[b]{2}{*}{ Item } & \multicolumn{4}{|l|}{ Scales } \\
\hline & $M C R B R S$ & $C B S$ & $K A S 2$ & $B S S$ \\
\hline Mobility & + & & & \\
\hline Orientation & + & & & \\
\hline Continence & + & + & & \\
\hline Communication & + & + & & \\
\hline Cooperation & + & + & & \\
\hline Over/underactivity & + & + & & \\
\hline Memory & + & & + & \\
\hline Dressing & + & + & + & \\
\hline Feeding & + & + & + & \\
\hline Cleanliness & + & + & + & \\
\hline Appearance & & + & & \\
\hline Antisocial behaviour & & + & & \\
\hline Productive activity & & + & & \\
\hline Laughs/talks to self & & + & & \\
\hline Hallucinated & & + & & \\
\hline Deluded & & + & & \\
\hline Postures/mannerisms & & + & & \\
\hline Obsessional rituals & & + & & \\
\hline Variability of behaviour & & + & & \\
\hline Compliance with medication & & + & & \\
\hline Social contact/withdrawal & & + & + & \\
\hline Work & & + & + & + \\
\hline Leisure pursuits & & + & + & + \\
\hline Housework & & & + & \\
\hline Finances & & & + & \\
\hline Shopping & & & + & \\
\hline Cares for Children & & & + & \\
\hline Church & & & + & \\
\hline Supports family & & & + & \\
\hline Family cohesion & & & + & + \\
\hline Legal offences & & & & + \\
\hline Sexual problems & & & & + \\
\hline Alcohol abuse & & & & + \\
\hline
\end{tabular}

MCRBRS = Modified Crichton Royal Behavioural Rating Scale; CBS = Current Behaviour Schedule; KAS2 = Katz Adjustment Scales form 2; BSS = Bond's Social Scale. 
scales. They were devised for rating adult psychiatric patients, and normative data are available for informant ratings. ${ }^{36}$ The time covered is the last few weeks.

Bond's Social Scale (BSS) ${ }^{14}{ }^{15}$ was specifically devised for rating social outcome after head injury. It consists of six items rated on 3 to 5 point scales, based on information obtained from both subject and informant. No time interval is specified.

In addition to the checklist ratings above, three other types of rating were made. Firstly, the initial time off work since injury was noted for the 46 subjects who were in full-time employment or higher education at the time of the accident. Because patients were seen at varying intervals after the injury, the initial time off work was expressed as a percentage of the time from injury to assessment (TOW\%). Secondly, some global ratings were made using the Global Assessment Scale (GAS) and the Glasgow Outcome Scales. The $\mathrm{GAS}^{3738}$ is a 100 point scale rating overall level of function using information from all available sources; it was designed for use with psychiatric patients, and refers to the lowest level of function in the past week. The Glasgow Outcome Scale $(G O S)^{20}$ was specifically designed to measure overall outcome after head injury, rated on a 5 point scale ranging from death to good recovery. An extended version (GOSE) was subsequently described, ${ }^{21}$ in which the three better outcome categories were each subdivided into two, to create an 8 point scale. For this study, operational definitions of the subdivisions were made. ${ }^{39}$ The sources of information and time period covered are not specified.

\section{Results}

Assessments were made on 56 patients, and a complete data set (including time off work) was obtained in 38 of the 56 subjects, 46 were male; the median age at injury was 26 years (range 16-64), and the median interval from injury to assessment was 15 months (range 1-41). Social class ${ }^{40}$ was I or II in 14 cases, III in 25 cases, IV or V in 11 cases, and 11 patients were not economically active. No academic qualifications had been attained in 22 cases, 25 subjects had CSE's or O-levels, five had A-levels and four were graduates. In 53 cases the informant was the spouse or parent of the subject; the remaining informants were a sister, a fiancee and a lifelong friend. Except for one case, informants were interviewed separately from the subjects.

The post-traumatic amnesia ranged from 0 to 12 weeks (median 10 days). Using the criteria of Jennett ${ }^{41}$ seven subjects had very mild injuries, three had mild injuries, five had moderate injuries, seven had severe injuries, 20 had very severe injuries and 10 had extremely severe injuries. Of the remaining four subjects who experienced no PTA, two developed posttraumatic epilepsy and two had delayed PTA. ${ }^{42}$

The scores on the social scales are summarised in table 2 by the median and range on each test. For scales which conform to a normal distribution, the mean and standard deviation are also tabulated. Histograms of the scores are portrayed elsewhere ${ }^{39}$ and summarised verbally in table 2 . Five of the scales did not conform to (and could not be transformed to) a normal distribution (as assessed by the KolmogorovSmirnov goodness of fit test): therefore, nonparametric statistics were used wherever possible. The reversed-J shape of the frequency histograms for MCRBRS and CBS indicates a ceiling effect in this patient group: the scales concentrate on severe impairments which are generally not present, and do not allow a useful spread of results. In contrast, the histogram of scores for TOW\%, is $\mathrm{J}$-shaped, suggesting both a floor effect (with many subjects off work permanently since injury), and also a ceiling effect for subjects having no time off work at all. In subsequent results, all scales have been adjusted so that high values consistently indicate impairment.

On five of the rating scales (GAS, MCRBRS, CBS, KASR2 and S2, and BSS) it was possible to compare the ratings obtained from subjects with those obtained from informants. The results are displayed in table 3, which shows good correlations between subject and informant ratings for all scales. The median scores are clearly very similar, and there are no statistically significant differences between them (Wilcoxon matched-pairs signed ranks test).

Table 2 Scores on social scales

\begin{tabular}{|c|c|c|c|c|c|c|c|c|}
\hline \multirow[b]{2}{*}{ Scale } & \multirow[b]{2}{*}{$(n)$} & \multicolumn{2}{|c|}{ Possible range } & \multicolumn{2}{|c|}{ Actual range } & \multirow[b]{2}{*}{ Median } & \multirow[b]{2}{*}{ Mean (SD) } & \multirow[b]{2}{*}{ Distribution } \\
\hline & & Best & Worst & Best & Worst & & & \\
\hline $\begin{array}{l}\text { MCRBRS } \\
\text { CBS } \\
\text { KASR2 } \\
\text { KASS2 } \\
\text { BSS } \\
\text { TOW\% } \% \\
\text { GAS } \\
\text { GOS } \\
\text { GOSE }\end{array}$ & $\begin{array}{l}(55) \\
(46) \\
(46) \\
(46) \\
(56) \\
(46) \\
(56) \\
(56) \\
(56)\end{array}$ & $\begin{array}{r}0 \\
50 \\
48 \\
48 \\
0 \\
0 \\
100 \\
5 \\
8\end{array}$ & $\begin{array}{r}38 \\
0 \\
16 \\
16 \\
100 \\
1 \\
1 \\
1\end{array}$ & $\begin{array}{r}0 \\
50 \\
46 \\
44 \\
1 \\
0 \\
75 \\
5 \\
8\end{array}$ & $\begin{array}{r}4 \\
26 \\
19 \\
24 \\
24 \\
100 \\
30 \\
3 \\
3\end{array}$ & $\begin{array}{r}0 \cdot 7 \\
45 \cdot 4 \\
33 \cdot 5 \\
35 \cdot 2 \\
8 \cdot 9 \\
64 \cdot 0 \\
56 \cdot 5 \\
4 \cdot 2 \\
6 \cdot 1\end{array}$ & $\begin{array}{l}- \\
\overline{33} .9(7 \cdot 5) \\
34.7(5.9) \\
9.6(5 \cdot 2) \\
\overline{56} .3(9.7) \\
-\end{array}$ & $\begin{array}{l}\text { reverse-J } \\
\text { reverse-J } \\
\text { normal } \\
\text { normal } \\
\text { normal } \\
\mathbf{J} \text { shaped } \\
\text { normal } \\
\wedge \text { shaped } \\
\wedge \text { shaped }\end{array}$ \\
\hline
\end{tabular}

MCRBRS = Modified Crichton Royal Behavioural Rating Scale; CBS = Current Behaviour Schedule; KASR2 = Katz Adjustment Scale form 2 (informant); KASS2 = Katz Adjustment Scale form 2 (subject); BSS = Bond Social Scale; TOW\% = Time Off Work (as percentage of time since injury); GAS = Global Assessment Scale; GOS Glasgow Outcome Scale; GOSE = Glasgow Outcome Scale Extended version. 
Table 3 Comparison of social scale scores derived from subject and informant ratings

\begin{tabular}{llllr}
\hline & & & \multicolumn{2}{c}{ Median score } \\
\cline { 4 - 5 } Scale & $n$ & rho & \multicolumn{1}{c}{$S$} & $I$ \\
\hline GAS & 56 & $+0.65^{*}$ & 60 & 60 \\
MCRBRS & 56 & $+0.53^{*}$ & 1 & 1 \\
CBS & 55 & $+0.81^{*}$ & 46 & 45 \\
KAS form 2 & 45 & $+0.78^{*}$ & 35 & 33 \\
BSS & 55 & $+0.77^{*}$ & 8 & 7 \\
\hline
\end{tabular}

$\mathrm{n}=$ number of paired subject-informant ratings; $\mathbf{S}=$ subject; $I=$ informant; $\quad$ GAS = Global Assessment $\quad$ Scale; MCRBRS = Modified Crichton Royal Behavioural Rating Scale; CBS = Current Behaviour Schedule; KAS = Katz Adjustment Scales; BSS = Bond's Social Scale.

${ }^{*} p<0.001$ (one-tailed).

The correlation matrix of the social scales is shown in table 4. It is clear that nearly all the scales correlate significantly with each other, the exception being TOW\%, which has significant correlations only with GOS and GOSE, neither of which is very high. The highest correlation is between GOS and GOSE, which is to be expected. The remaining correlations (excluding TOW\%) range from +0.31 to +0.78 , accounting for 10 to $61 \%$ of the variance.

The scales were then entered into a principal components analysis with varimax rotation, which produce two factors with an eigenvalue greater than 1 . The factor loadings of the rotated solution are illustrated in table 5 . The loadings express more succinctly the results of the non-parametric correlation matrix. All the scales except TOW\% load highly on the first factor. On the second factor, TOW\% loads highly and the Glasgow Outcome Scales have moderate loadings.

The findings can be summarised by concluding that social outcome after head injury is not unitary but heterogeneous in nature. The correlation matrix and principal components analysis support the use of two separate measures, namely performance of social expected activities and going to work. If a single mea- sure is to be used, the Glasgow Outcome Scales offer the best compromise, although the range of scores is narrow (5 points on the GOS and 8 points on the GOSE).

\section{Discussion}

The item content of most of the scales is concerned with performance of social roles ranging from a fairly basic level (activities of daily living) to fairly sophisticated aspects of citizenship (such as observing the law and going to church). Only one scale, the CBS, contained items directly relating to psychiatric symptoms; in this case, the symptoms were the more obvious ones of chronic schizophrenia. Only two of the patients were psychotic, so it is not surprising that no dimension of psychiatric symptoms emerged from the correlation matrix and principal components analysis. The findings here are thus different from those of authors who have included measures of psychiatric symptoms and satisfaction in their social ratings ${ }^{43-46}$ and indicate that it is possible to separate social performance from psychiatric symptoms. Also excluded from the present scales are measures of social conditions/deprivation, such as income, housing, and community facilities.

The comparison of subject with informant ratings shows a high level of agreement despite the severity of the head injuries sustained by most patients. The correlations obtained are much better than subject-informant correlations for residents of old people's homes $(r=+0.36, p<0.001)^{28}$ and generally better than for social performance of parents of one-year old children $(r=+0.29$. $p<0.05$ to $r=+0.72, p<0.001) .^{47}$

It is surprising when comparing the different social scales, that, within the area of performance of social roles, there appears to be a clear dichotomy between time off work and other indices of social performance. This cannot be regarded as an artefact of the principal

Table 4 Spearman rank-order correlations between social scales

\begin{tabular}{|c|c|c|c|c|c|c|c|c|c|}
\hline \multirow[b]{2}{*}{ Scale } & \multirow[b]{2}{*}{$(n)$} & \multicolumn{8}{|l|}{ Scales } \\
\hline & & $\begin{array}{l}\text { TOW\% } \\
\text { (46) }\end{array}$ & $\underset{(56)}{G O S}$ & $\begin{array}{l}\text { KASS2 } \\
(46)\end{array}$ & $\underset{(56)}{G O S E}$ & $\begin{array}{l}M C R B R S \\
(55)\end{array}$ & $\begin{array}{l}B S S \\
(56)\end{array}$ & $\begin{array}{l}G A S \\
(56)\end{array}$ & $\begin{array}{l}C B S \\
(55)\end{array}$ \\
\hline $\begin{array}{l}\text { KASR2 } \\
\text { CBS } \\
\text { GAS } \\
\text { BSS } \\
\text { MCRBRS } \\
\text { GOSE } \\
\text { KASS2 } \\
\text { GOS }\end{array}$ & $\begin{array}{l}(46) \\
(55) \\
(56) \\
(56) \\
(55) \\
(56) \\
(46) \\
(56)\end{array}$ & $\begin{array}{l}0.03 \\
0.04 \\
0.06 \\
0.09 \\
0.04 \\
0.27^{*} \\
0.17 \\
0.36 \dagger\end{array}$ & $\begin{array}{l}0.49 \ddagger \\
0.48 \ddagger \\
0.59 \ddagger \\
0.55 \ddagger \\
0.39 \ddagger \\
0.95 \ddagger \\
0.38 \ddagger\end{array}$ & $\begin{array}{l}0 \cdot 78 \ddagger \\
0 \cdot 61 \ddagger \\
0 \cdot 65 \ddagger \\
0 \cdot 35 \ddagger \\
0 \cdot 31^{*} \\
0 \cdot 39+\end{array}$ & $\begin{array}{l}0.57 \ddagger \\
0.52 \ddagger \\
0.60 \ddagger \\
0.63 \ddagger \\
0.46 \ddagger\end{array}$ & $\begin{array}{l}0 \cdot 58 \ddagger \\
0 \cdot 58 \ddagger \\
0 \cdot 57 \ddagger \\
0 \cdot 56 \ddagger\end{array}$ & $\begin{array}{l}0.60 \ddagger \\
0.59 \ddagger \\
0.56 \dagger\end{array}$ & $\begin{array}{l}0.78_{+}^{+} \\
0.76_{+}^{+}\end{array}$ & $0 \cdot 78_{+}^{+}$ \\
\hline
\end{tabular}

TOW\% $=$ Time off Work as percentage of time since injury; GOSE = Glasgow Outcome Scale Extended version; GAS = Global Assessment Scale; KAS = Katz Adjustment Scales; CBS = Current Behaviour Schedule; MCRBRS = Modified Crichton Royal Behavioural Rating Scale; BSS = Bond's Social Scale; GOS = Glasgow Outcome Scale.

${ }^{*} \mathrm{p}<0.05 ; \mathrm{tp}<0.01 ; \ddagger \mathrm{p}<0.001$ (one-tailed). 
Table 5 Principal components analysis of social scales

\begin{tabular}{llc}
\hline & \multicolumn{2}{l}{ Factor loadings } \\
\cline { 2 - 3 } Scale & Factor 1 & Factor 2 \\
\hline KASR2 & 0.91 & 0.01 \\
CBS & 0.89 & 0.19 \\
GAS & 0.88 & 0.09 \\
BSS & 0.77 & 0.19 \\
MCRBRS & 0.77 & 0.04 \\
GOSE & 0.75 & 0.56 \\
KASS2 & 0.74 & 0.22 \\
GOS & 0.61 & 0.66 \\
TOW\% & 0.06 & 0.90 \\
Variance accounted for & $62.0 \%$ & $13.5 \%$ \\
\hline
\end{tabular}

KAS $=$ Katz Adjustment Scales; $\quad$ CBS $=$ Current Behaviour Schedule; GAS = Global Assessment Scale; BSS = Bond's Social Scale; MCRBRS = Modified Crichton Royal Behavioural Rating Scale; $\quad$ GOSE = Glasgow Outcome Scale Extended version; GOS = Glasgow Outcome Scale; TOW $\%=$ Time off Work as percentage of time since injury.

components analysis, as it is supported by the nonparametric correlation matrix. The finding is even more surprising in that most of the performance scales do include an actual item about work, so one would predict at least some overlap in scores due to the overlap in content.

A similar finding has been reported by Ellsworth et al. $^{43}$ In a factor analysis of psychiatric symptoms and social functioning in psychiatric patients, two separate factors described the social function: these two factors were described as "work productivity" and "outside social activity", and correspond to the factors obtained in the current study of time off work and performance of other social expected activities.

This result indicates that it is inappropriate to view social performance as a unitary hierarchial phenomenon, in which going to work subsumes the successful performance of other social roles. Although this model may apply in some cases, the overall independence of time off work from other social measures suggests that going to work is carried out at the expense of other social activities in some cases. This supposition is borne out by clinical observations on patients.

The patients studied are certainly not a representative sample of patients suffering head injury. They are highly selected by a three or four stage consultation process (G.P./solicitor, hospital specialist, neurologist, neuropsychologist) which is likely to have biased the sample with respect to the base population of head-injured patients. In comparison with a prospectively studied series of consecutive admissions ${ }^{12}$ they have more severe head injuries. This bias means that the present study can have no epidemiological implications concerning the prevalence of problems in a representative sample of head injured patients. This bias also means that caution should be exercised in extrapolating the findings to other samples of head injured subjects. However, in carrying out a correlational study of this nature, the most important point is to include an adequate range of observations. ${ }^{48}$ The present series of patients includes a wide range of head injury severity (as measured by PTA), a wide range of time off work and a fairly wide range of other social impairments; only the most profoundly handicapped were excluded from assessment. The general tenor of the findings is thus likely to be applicable to other series of head-injured patients unless they are very narrowly defined or profoundly handicapped (that is, requiring continuous in-patient care).

The heterogeneity of social outcome suggests that future studies should include separate measures of work and general social function. This approach has been adopted in the Glasgow Assessment Schedule, ${ }^{22}$ which was published after the current work was completed. In the present study, the most suitable measures of general performances were the KAS R2 and S2 scales and the BSS, which all gave a reasonable range of results, and showed good agreement between subject and informant ratings. The CBS and MCRBRS suffered from ceiling effects in this client group, resulting in a narrow range of results. The GAS mixes psychiatric symptoms with social function and is thus less suitable from a theoretical point of view. The Glasgow Outcome Scales provided a good overall measure and would be suitable if a single outcome measure were desired, because they also correlate significantly with time off work; their main drawback is the narrow range of ratings produced, which allows little room for the measurement of change. On these grounds, the GOSE can be regarded as a significant improvement on the original GOS. In actual use, the GOSE appeared far more satisfactory compared to the rather laconic GOS, particularly as the first two categories (death and persistent vegetative states) were not relevant to the current study. In comparing published work, it is always possible to collapse the categories of the GOSE for comparison with the GOS, but the reverse is not possible. It is clear that time off work is a useful measure. However, it appears to represent only some of the truth about social outcome after head injury, and should be supplemented by other measures for a complete picture. This should be borne in mind when interpreting the numerous studies where time off work is the only measure of social outcome, and whendesigning new studies of outcome after head injury.

I am grateful to the consultants who allowed me to study their patients, the individual patients, and their informants. This work was made possible by grant number A/8/1245 from the National Fund for Crippling Diseases (Action Research for the Crippled 
Child). Special thanks are due to my research supervisor, Dr Christine Dean, who oversaw the analysis and presentation of the data.

\section{References}

1 Kerr TA, Kay DWK, Lassman LP. Characteristics of patients, type of accident, and mortality in a consecutive series of head injuries admitted to a neurosurgical unit. $\mathrm{Br} J$ Preventive and Social Medicine 1971;25:179-85.

2 Field JH. Epidemiology of Head Injuries in England and Waleswith particular application to rehabilitation. London: HMSO, 1976.

3 Broe A, et al. The nature and effects of brain damage following severe head injury in young subjects. In: Dinning TAR, Connelly TJ, eds. Head Injuries-An Integrated Approach. Brisbane: John Wiley \& Sons, 1981:92-97.

4 Alexander MP. Traumatic brain injury. In: Benson DF, Blumer D, eds. Psychiatric Aspects of Neurologic Disease Volume II. New York: Grune \& Stratton, 1982:219-49.

5 Brooks N. Introduction In: Brooks N, ed. Closed Head Injury: Psychological, Social and Family Consequences. Oxford: Oxford University Press, 1984:1-3.

6 World Health Organization. International Classification of Impairments, Disabilities, and Handicaps. Geneva: WHO, 1980.

7 Gruenberg EM. The social breakdown syndrome-some origins. Am J Psychiatry 1967;123:1481-9.

8 Adler A. Mental symptoms following head injury: a statistical analysis of two hundred cases. Arch Neurol Psychiatry 1945;53:34-43.

9 Denny-Brown D. Disability arising from closed head injury. JAMA 1945;127:429-36.

10 Steadman JH, Graham JG. Head injuries: an analysis and followup study. Proc $R$ Soc Med 1970;63:23-29.

11 Oddy $M$, Humphrey $M$, Uttley $D$. Subjective impairment and social recovery after closed head injury. $J$ Neurol Neurosurg Psychiatry 1978;41:611-6.

12 Cartlidge NEF, Shaw DA. Head Injury. London: WB Saunders Company Ltd, 1981.

13 Rimel RW, Giordani B, Barth JT, Boll TJ, Jane JA. Disability caused by minor head injury. Neurosurgery 1981;9:221-8.

14 Bond MR. Assessment of the psychosocial outcome after severe head injury. In: Outcome of Severe Damage to the Nervous System-CIBA Foundation Symposium No. 34 (new series). Amsterdam: Elsevier:-Excerpta Medica, 1975:141-57.

15 Bond MR. Assessment of the psychosocial outcome after severe head injury. Acta Neurochir (Wein) 1976;34:57-70.

16 Keshaven MS, Channabasavanna SM, Reddy GNN. Post traumatic psychiatric disturbances: patterns and predictors of outcome. Br J Psychiatry 1981;138:157-60.

17 Newton A, Johnson DA. Social adjustment and interaction after severe head injury. Br J Clin Psychol 1985;24:225-34.

18 Gronwall D. Performance changes during recovery from closed head injury. Proc Australian Association of Neurologists 1976;13:143-7.

19 Rutherford WH, Merrett JD, McDonald JR. Symptoms at one year following concussion from minor head injuries. Injury 1979;10:225-30.

20 Jennett B, Bond M. Assessment of outcome after severe brain damage: a practical scale. Lancet 1975;i:480-4.

21 Jennett B, Snoek J, Bond MR, Brooks N. Disability after severe head injury: Observations on the use of the Glasgow Outcome Scale. J Neurol Neurosurg Psychiatry 1981;44:285-93.

22 Livingston MG, Livingston HM. The Glasgow Assessment Schedule: clinical and research assessment of head injury outcome. International Rehabilitation Medicine 1985;7:145-9.

23 Weissman MM. The assessment of social adjustment-a review of techniques. Arch Gen Psychiatry 1975;32:357-65.

24 Weissman MM, Sholomkas D, John K. The assessment of social adjustment-an update. Arch Gen Psychiatry 1981;38:1250-8.

$25 \mathrm{Katschnig} H$. Methods for measuring social adjustment. In: Helgason T, ed. Methodology in Evaluation of Psychiatric Treatment. Cambridge: Cambridge University Press, 1983:205-18.
26 Jennett B. The Measurement of Outcome. In: Brooks N, ed. Closed Head Injury: Psychological, Social and Family Consequences. Oxford: Oxford University Press, 1984:37-43.

27 Kuriansky J, Gurland B. The performance test of activities of daily living. Int J Ageing Hum Dev 1976;7:343-52.

28 Little AG, Hemsley DR, Volans PJ, Bergmann K. The relationship between alternative assessment of self-care ability in the elderly. Br J Clin Psychol 1986;25:51-9.

29 Wing JK, Cooper JE, Sartorius N. The Measurement and Classification of Psychiatric Symptoms. Cambridge: Cambridge University Press, 1974.

30 Wilkin D, Jolley D. Behavioural problems among old people in geriatric wards, psycho-geriatric wards and residential homes 1976-1978. Research Report number 1. West Didsbury, Manchester: Research Section, Psycho-geriatric Unit, University Hospital of South Manchester, 1979.

31 Robinson RA. Some problems of clinical trials in elderly people. Gerontologia Clinica 1961;3:247-57.

32 Charlesworth A, Wilkin D. Dependency among old people in geriatric wards, psycho-geriatric wards and residential homes 1977-1981. Research report number 6. West Didsbury, Manchester: Research Section, Psycho-geriatric Unit, University Hospital of South Manchester, 1982.

33 Owens DGC, Johnstone EC. The disabilities of chronic schizophrenia - their nature and the factors contributing to their development. Br J Psychiatry 1980;136:384-95.

34 Johnstone EC, Owens DGC, Frith CD, Calvert LM. Institutionalization and the outcome of functional psychoses. $\mathrm{Br} J$ Psychiatry 1985;146:36-44.

35 Katz MM, Lyerly SB. Methods for measuring adjustment and social behaviour in the community: rationale, description, discriminative validity and scale development. Psychol Rep 1963;13:503-35.

36 Hogarty GE, Katz MM. Norms of adjustment and social behaviour. Arch Gen Psychiatry 1971;25:470-80.

37 Endicott J, Spitzer RL, Fleiss JL, Cotten J. The Global Assessment Scale. A procedure for measuring overall severity of psychiatric disturbance. Arch of Gen Psychiatry 1976;33: 766-71.

38 Spitzer RL, Gibbon M, Endicott J. Global Assessment Scale (GAS). New York: Biometrics Research, New York State Psychiatric Institute, 1978.

39 Dodwell DJF. Neuropsychological and Psychiatric Disorders following Head Injury. M.D. thesis, University of Manchester, 1986.

40 Office of Population Censuses and Surveys. Classification of Occupations. London: HMSO, 1980.

41 Jennett B. Assessment of the severity of head injury. J Neurol, Neurosurg Psychiatry 1976;39:647-55.

42 Russell WR. The Traumatic Amnesias. London: Oxford University Press, 1971.

43 Ellsworth RB, Foster L, Childers B, Arthur G, Kroeker D. Hospital and community adjustment as perceived by psychiatric patients, their families and staff. Journal of Consulting and Clinical Psychology Monograph Supplement 1968;32:(5) part 2:1-41.

44 Hogarty GE, Katz MM, Lowery HA. Identifying candidates from a normal population for a community mental health program. In: Monroe RR, Klee GD, Brody EB, eds. Psychiatric Epidemiology and Mental Health Planning. American Psychiatric Association Research Report No. 22. Washington D.C.: American Psychiatric Association 1967:220-34.

45 Linn MW, Sculthorpe WB, Evje M, Slater PH, Goodman SP. A social dysfunction rating scale. J Psychiatric Res 1969;6: 299-306.

46 Paykel ES, Weissman M, Prusoff BA, Tonks CM. Dimensions of social adjustment in depressed women. $J$ Nerv Ment Dis 1971;152:158-72.

47 Cooper P, Osborn M, Gath D, Feggetter G. Evaluation of a modified self-report measure of social adjustment. Br J Psychiatry 1982;141:68-75.

48 Downie NM, Heath RW. Basic Statistical Methods. New York: Harper \& Row, 1970:95-97. 